\title{
BIOMECHANICS OF HYPHAL GROWTH
}

\author{
Roger R. Lew \\ Department of Biology \\ York University \\ 4700 Keele Street \\ Toronto Canada \\ Email:planters@yorku.ca
}

ABSTRACT. Fungi invade new territory by tubular extensions (hyphae) that ramify through the substrate to form a mycelial network. The growth of the hyphae has physical components: The biomechanical nature of the fungal wall protects the cytoplasm from the external environment. The internal hydrostatic pressure (turgor) provides the driving force for physical expansion of the wall at the hyphal tip during growth. The biomechanics that govern hyphal growth are explored.

I. Introduction (why hyphal growth?)

II. Physical Description of the Hyphae
A. Biomechanics
B. Turgor Measurements
C. Osmotic Pressure

III. Turgor and Growth

IV. Turgor Regulation

V. Cytoplasmic movement (mass flow)

A. Low Reynolds number hydrodynamics

B. Effect of hyphal pores

VI. Penetration (invasive growth)

\section{References}

Figure 1: Hyphal stress mechanics.

Figure 2: Model of hyphal expansion.

Figure 3: Turgor regulation of fungal hypha.

Figure 4: Genes functioning in turgor regulation.

Figure 5: Micro-fluidics of a hypha.

Lew RR (2019) Biomechanics of hyphal growth. The Mycota. Volume VIII: Biology of the Fungal Cell (3rd edition). Edited by Hoffmeister D and Gressler M. pages 83-94. 


\section{Introduction (why hyphal growth?)}

Fungi are a complex group of organisms, comprised of at least three related phylogenetic clades. They are - for the most partsaprobes, but can also be pathogens and symbiotic partners. As saprobes, their ability to decompose organic material is crucial to global carbon cycling. They have a characteristic growth pattern that is fundamentally pleiomorphic in nature. Leading hyphae extend into new territory to find organic material to fuel continued growth. Much of the digestion of organic material in the invaded territory occurs through the action of biodegrading enzymes secreted from the fungal cells. Behind the leading hyphae, a mycelial network of considerable complexity develops, ramifying through the substrate and taking up nutrients that have been decomposed through the action of the biodegrading enzymes. These nutrients in turn provide the metabolic energy necessary for continued growth at the hyphal colony edge. In practically all circumstances, growth requires that the hyphae be able to physically penetrate the substrate. Penetration is also a growth characteristic of pathogens and symbionts, since in both cases, the fungi must 'invade' the host tissue and/or cells. The pleiomorphic nature of growth patterning arises from the ability of the fungi to adapt and grow in new locations dependent on local nutrient supply and obstacles to growth.

Like most bacteria and plants, fungi have an extracellular wall that provides a protective structure surrounding the cytoplasm. Because the concentrations of various solutes within the hyphal cell are usually higher than that in the external environment, water is taken up, creating a hydrostatic pressure - turgor - that puts the outer wall under considerable tensile stress. With a few exceptions that will be discussed later, turgor is the major driving force for cell expansion, and the penetration of substrates by the fungus.

In this chapter, recent advances in our understanding of the biomechanics of hyphal growth will be presented.

\section{Physical Description of the Hyphae}

\section{A. Biomechanics}

One analogy for pressurized fungal cells are tires of bicycles and cars. When pressure expands the tire, it rigidifies the outer structure of the tire. The outer structure is often a composite that includes wire to withstand the tensile stress caused by the internal pressure; the wire is embedded in an elastic material, rubber. The fungal wall similarly provides elements to provide tensile strength and elastic flexibility. The composite wall structure is far more complex than a tire, comprised of interacting polymeric molecules and can be considered a nano-structural bio-composite material.

For pressurized structures like hyphae, the mechanics of hyphal strength are shown in Figure 1. Cell wall mechanical strength is explained clearly by Nobel (1991). When the cell is under pressure, the outer structural wall experiences tension along its surface. The magnitude of the tension varies dependent on the geometry and direction of the tensional stress. For a sphere, the tangential stress $\left(\sigma_{\mathrm{s}}\right)$ (in units of Pascals) is described by $\sigma_{\mathrm{s}}=r P / 2 t$, where $r$ is the 
radius of the sphere, $P$ is the pressure, and $t$ is the thickness of the wall. Basically, tensional stress increases with either increasing size or pressure, and decreases with increasing wall thickness. The same tension is experienced by cylindrical structures in the longitudinal direction (the direction of cylindrical elongation) $\left(\sigma_{\mathrm{t}}=r P / 2 t\right)$, but not tangentially (that is, radial expansion of the cylindrical cell): $\sigma_{\mathrm{r}}=r P / t$. The latter tangential stress is sometimes referred to as circumferential or hoop stress. For a simplified geometry of a hyphal

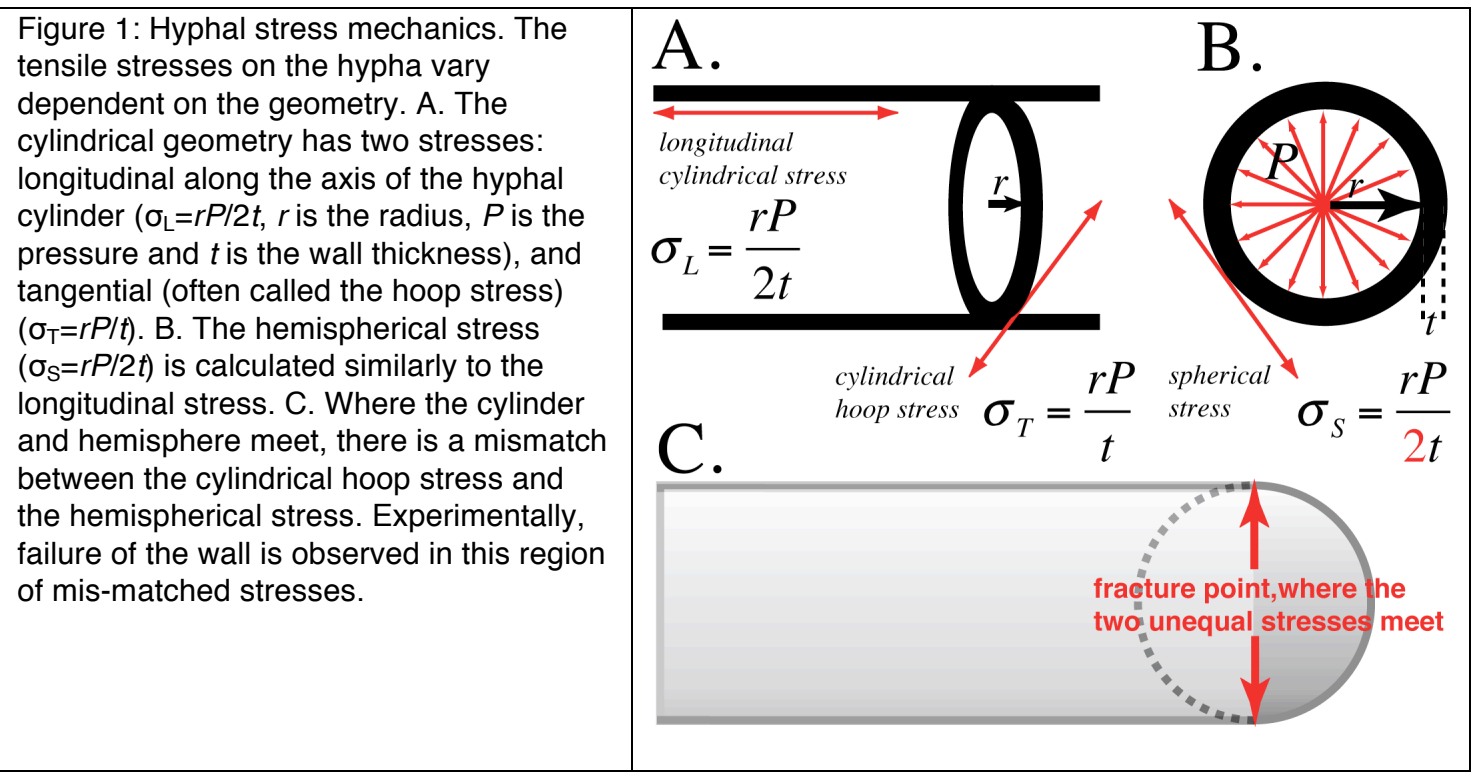

tip geometry of a hyphal tip (a cylinder with a hemisphere at the tip), the tensile stress is unequal at the juncture between the cylinder and the hemispherical tip. In fact, the juncture does appear to be a common location for cell rupture under high pressure (experimentally observed in root hairs of higher plants; Lew, 1996).

The tensional stresses on the wall have to be counteracted by the wall. The strength of the wall is related directly to the cell wall material and its orientation within the cell wall. Because of the complex polymer-based nature of the structural architecture, biocomposites do not lend themselves to simple engineering analysis. Niklas and Spatz (2012) describe the complexity of the strength of bio-composites in detail. For a hypha, there are three biomechanical responses to stress that need to be considered: elasticity, stiffness (or rigidity), and plasticity (Figure 2).

As pressure is applied internally, the wall can respond elastically, similar to a rubber band: expanding and contracting freely as the pressure is varied. But there is a limit beyond which elasticity fails as the pressure is increased because the stretching 'thins' the wall, increasing the tensional stress. At higher pressure, cell walls do tend to lose their ability to respond elastically. So, either wall 'thinning', or increased rigidity, or both, eventually cause the cell wall to rupture (Figure 2A). 


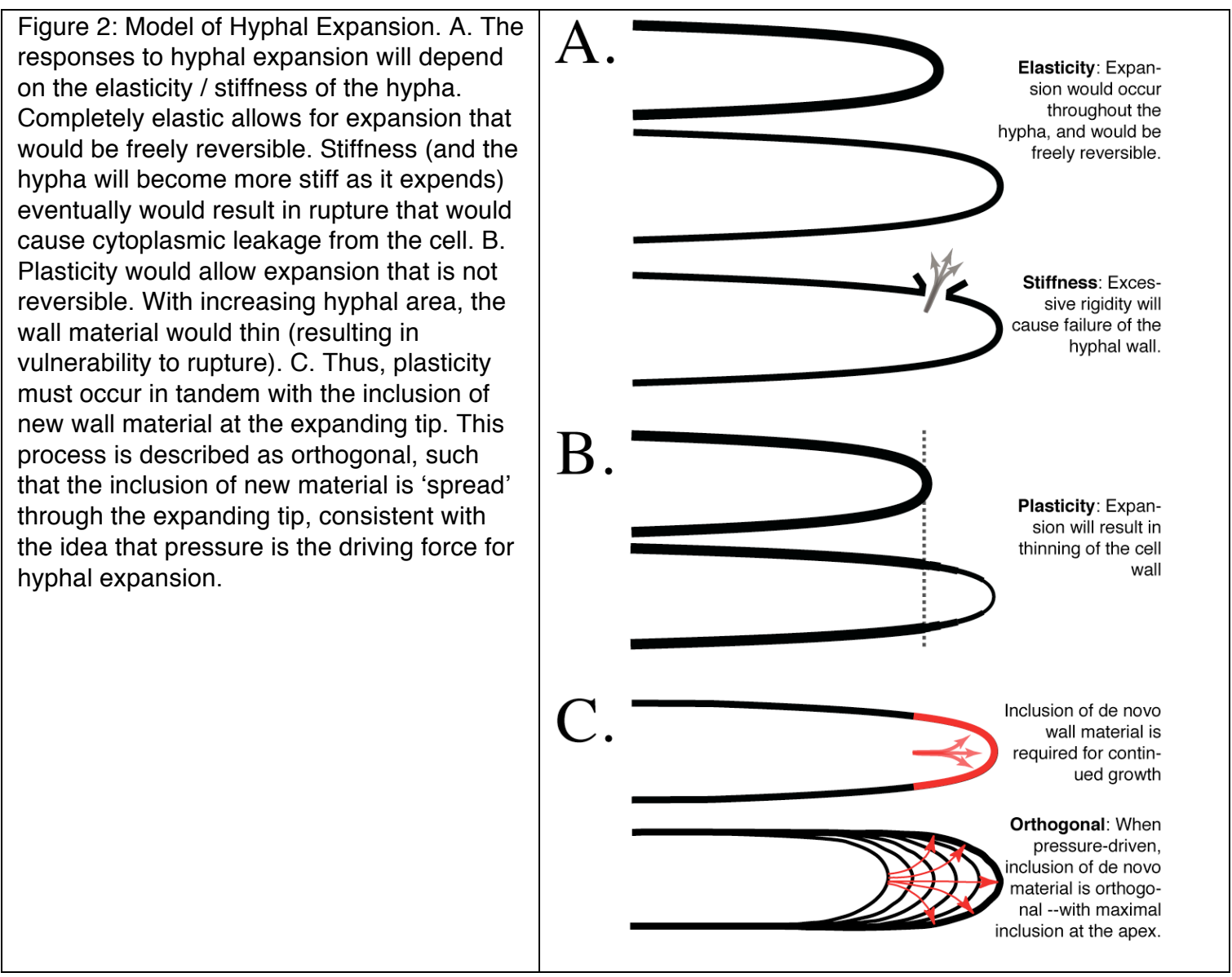

Plasticity refers to the ability of the material to change its shape. Ideally, this is not reversible. But biological materials are often viscoelastic, because the deformation is partially reversible if the stress is alleviated. Viscoelastic deformation is the common model for cellular expansion in walled cells; it provides an accurate framework to explore the nature of spatially localized expansion in cells across the plant and fungal kingdoms. Viscoelastic responses can vary with the magnitude of the turgor, formalized by Lockhart (1965), who proposed that irreversible cell wall expansion is described by $\mathrm{r} \Phi\left(\mathrm{P}-\mathrm{P}_{\mathrm{E}}\right)$, where $\mathrm{r}$ is the radius, $\Phi$ is the extensibility of the wall, $\mathrm{P}$ is the turgor pressure, and $\mathrm{P}_{\mathrm{E}}$ is the threshold pressure required before expansion will occur. Above the threshold pressure, the wall becomes plastic and deformable. If the wall composition can be modified to be more viscoelastic at specific locations, then that is where expansion will occur. For hyphal growth, the hyphal tip is the site of expansion, and therefore the tip must be viscoelastic. Direct experimental evidence in support of regulated viscoelastic properties is not easy to come by. The most compelling was obtained from work on the alga Chara corallina (Proseus and Boyer, 2006, 2007), which is experimentally accessible because of its large size. In Chara, the plasticity (or extensibility of the elongating cylinder) is regulated by calcium cross-linkage of pectin in the wall. The more cross-linkages there are, the lower the plasticity of the wall. The nature of regulation of the cell wall plasticity in fungi must be different, since pectin does not contribute to fungal cell wall 
composition (Free, 2013). Instead, re-modeling of the wall appears to rely upon the activity of various hydrolases (Adams, 2004) that are spatiotemporally regulated.

Viscoelasticity alone is insufficient to allow for continued cellular expansion because the wall thins as its surface area increases (Figure 2B). Thus, new membrane and wall material must be incorporated as the tip extends (Figure 2C). Experimental measurements show that hyphal tip expansion is orthogonal (Bartnicki-Garcia et al., 2000). That is, incorporation of new material occurs perpendicular to the hyphal tip surface as the tip extends, resulting in an orthogonal displacement of particles on the cell surface. Bartnicki-Garcia et al. (2000) argue that orthogonal growth must be pressure-driven, since only pressure would apply a force that is always perpendicular to the inside surface of the hyphae. Other experimental evidence certainly supports the central role of turgor in growth.

The elasticity/stiffness/plasticity of the hyphae is described experimentally by a plot of applied force versus deformation (or a stress versus strain relation in the terminology of engineering). Niklas and Spatz (2012) explain the stress-strain relations of biological materials. Basically, the stress is the force applied to the cell (pressure in our case), while the strain is the deformation of the cell caused by the stress. For an elastic material, the relation would be linear: apply a tensional stress, the material will stretch, decrease the tension and the material will return to its original shape. A rigid or stiff material won't undergo deformation. And plastic deformation is irreversible. Generally, the slope of the stress-strain relation (called the modulus of elasticity) is used to quantitatively describe how much deformation occurs. A shallow slope represents a biomaterial that is easily deformed; a steeper slope indicates a stiff or rigid biomaterial. An example of stress-strain relations for turgid hyphae is presented in section III.

\section{B. Turgor Measurements}

There are a number of techniques that can be used to measure the turgor pressure of a walled cell. Some are indirect - such as measuring the osmolarity that causes incipient plasmolysis, or ball tonometry. One is very direct -impalement of the cell with a pressure probe. The pressure probe technique (Zimmerman et al., 1969) has been used in a wide range of cells (plant, algal and fungal) for many decades. Hüsken et al. (1978) provide a detailed description of the technique.

The value of direct pressure measurements is clear. The pressure can be continuously monitored during responses to various treatments. In the hands of an experienced cell biophysicist, the cell seldom exhibits any sign of damage, and in fact can continue to grow after impalement with the pressure probe (Lew, 2005). Upon impalement with a silicon oil-filled micropipette, turgor pushes the oil/cytoplasm meniscus into the micropipette. Pressure is applied to push the meniscus back to the micropipette tip. The applied pressure is an estimate of the initial turgor. For fungal hyphae, some of the more biophysical measurements, such as hydraulic conductivity, may or may not be measurable, because the cell 'unit' may not be finite (instead, it is a continual tube of indeterminate length). 
An alternative method of measuring turgor is an indirect one: ball tonometry (Lintilhac, et al., 2000). In this technique, a ball of known (and small) size is pressed against the surface of the cell being measured. The applied force and the indentation contact area are used to estimate the turgor. The technique is limited: Only surface cells with elastic cell wall responses are measurable.

Despite the limitations, ball tonometry does offer a dynamic way to assess responses to forces coming from the outside of the cell. For example, how much force causes a growth response? Can the applied forces induce a shift to a penetration growth pattern? These and other questions may become directly answerable using ball tonometry.

\section{Osmotic Pressure}

The turgor pressure of a walled cell arises from the differences in the osmolarity inside and outside the cell, often referred to as the osmotic pressure. This is described by the equation: $\Delta \mathrm{P}=\mathrm{RT}\left(\mathrm{c}_{\mathrm{i}}-\right.$ $\mathrm{c}_{\mathrm{o}}$ ), in which $\Delta \mathrm{P}$ is the pressure, $\mathrm{R}$ is the gas constant $(8.314 \mathrm{~L} \mathrm{kPa} \mathrm{K}$ ' $\left.\mathrm{mol}^{-1}\right), \mathrm{T}$ is the temperature $(\mathrm{K})$, and $\mathrm{c}_{\mathrm{i}}$ and $\mathrm{c}_{\text {。 }}$ are the concentrations (mol L-1) of osmotically active solutes inside and outside the cell, respectively. For a normal turgor of $600 \mathrm{kPa}$ at room temperature $(293 \mathrm{~K})$, the cytoplasmic concentration of osmotically active solutes would have to be about $250 \mathrm{mM}$ higher than the external concentration. During growth, the cell volume increases due to water influx, so that the osmotically active solutes inside the cell would become diluted, decreasing turgor. To maintain turgor during expansive growth, osmotically active solutes must be taken up and/or synthesized de novo.

\section{Turgor and Growth}

Does turgor 'drive' growth? Apparently it does. When turgor is adjusted by increasing the external concentration of osmolytes, the turgor (due to the difference in osmolyte concentrations inside and outside of the cell) declines, as does growth. An example of the relation between turgor and growth (and subsequent turgor regulation) is shown in Figure 3 for the fungus Neurospora crassa (Lew and Nasserifar, 2009). After addition of external osmoticum, the hyphal turgor declines precipitously (figure 3A); growth rates drop at the same time (figure 3B). The decline in turgor also results in a decrease in hyphal volume (figure 3C). Micrographs of a hypha impaled with a pressure probe show the hyphal volume shrinkage at the times specified (figure 3D). Over time, turgor, growth and hyphal volume increase as a consequence of turgor regulation mechanisms to be described in a later section.

The biomechanical behaviour of the hyphae can be inferred from the relation between turgor (stress) and hyphal shrinkage (strain) (figure $3 \mathrm{E}$ ). The slopes of the curve (the modulus of elasticity) provide a measure of the extent of strain that occurs. In general, at low turgor, the hyphae are readily deformed; thus the modulus of elasticity is fairly low (about $0.4 \mathrm{MPa}$ ). As turgor is increased, the hyphal wall expands and becomes stiffer, resulting in a higher modulus (about $1.8 \mathrm{MPa}$ ). The full range of the modulus is not being measured (that is, at turgor higher than normal), but the modulus would be expected to increase even more as the wall was stretched to its limit. For 
walled plants and algal cells, moduli vary from about 1 (very elastic) to $60 \mathrm{MPa}$ (very stiff) (Zimmerman, 1978).

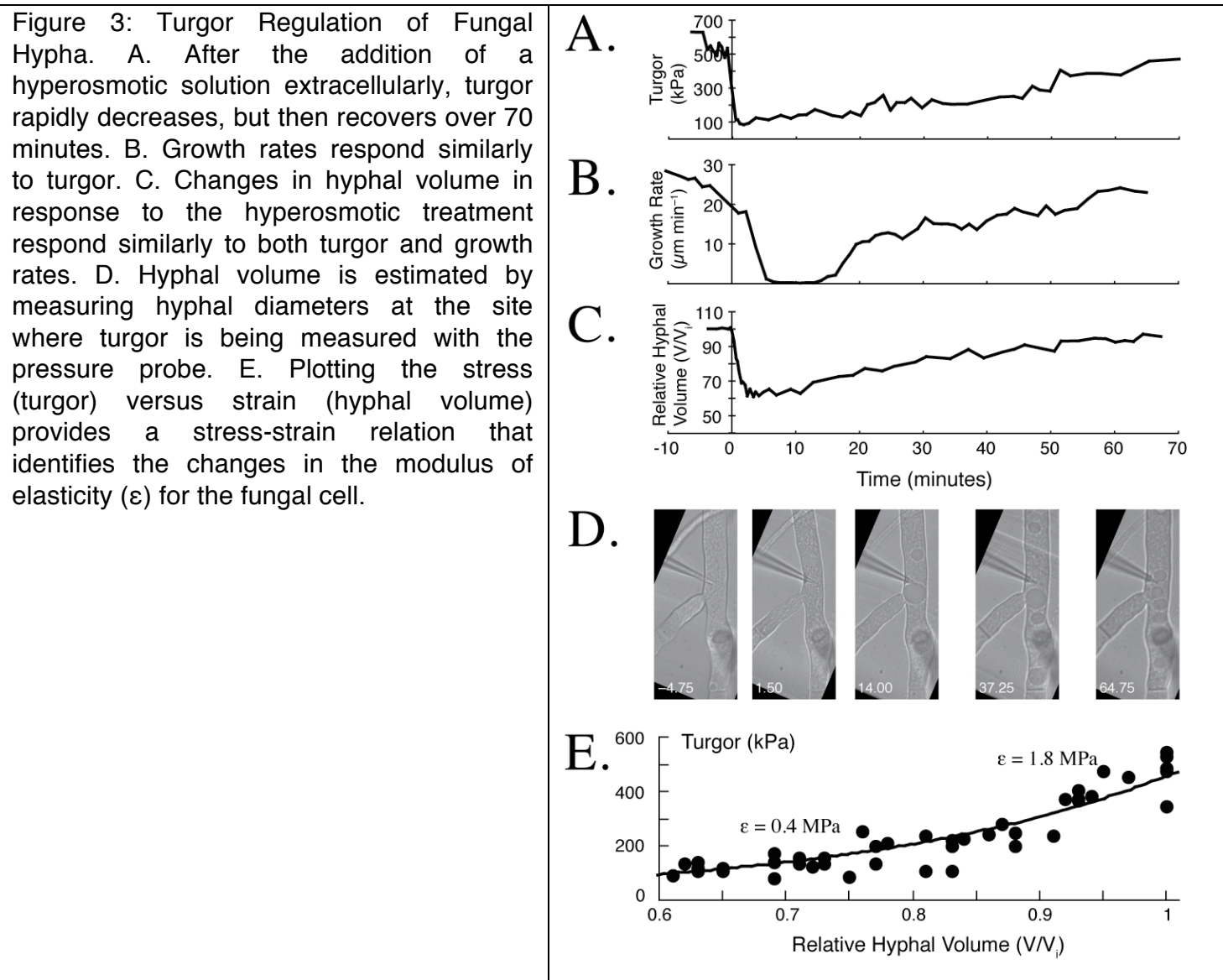

The basic observation is that there is a clear relation between turgor and hyphal growth. And in response to hyperosmotic conditions, the turgor is regulated, returning to its initial value (prior to the hyperosmotic treatment) in about 60 minutes.

It is not always the case that there is such a straightforward relation between turgor and growth. The Oomycetes are one example of a hyphal organism that does not appear to regulate turgor (Lew et al., 2004). Kaminskyj et al. (1992) reported that the oomycete Saprolegnia ferax does require turgor to grow, but growth rates are independent of turgor over a range of about 100 to $300 \mathrm{kPa}$. Harold et al. (1996) reported that this hyphal organism was able to grow even in the absence of any measurable turgor. What is difficult to determine is whether growth independent of turgor is due to changes in the threshold pressure required for growth, meaning that the viscoelastic properties of the wall are increasing at lower turgor. There is an alternative mechanism for growth that may explain hyphal extension in the absence of turgor - apical extension caused by the cytoskeleton (Heath and Steinberg, 1999). An unusual example of growth in the absence of turgor is the slime mutant of Neurospora crassa (Emerson, 1963; Perkins et al., 1982): This is a 
triple mutant $(f z ; s g ; o s-1)$ that is wall-less, osmosensitive, and exhibits a phenotype of ameboidal growth, with pseudopodial extensions. A role for the cytoskeleton in tip growth is indicated by analysis of cytoskeleton architecture in hyphae penetrating hard substrates (Walker et al., 2006). Certainly, the cytoskeleton does play a role in cytological organization within the growing hyphae (Lew, 2011).

\section{Turgor Regulation}

To begin with, we need to distinguish between osmotolerant growth and turgor regulation. Fungal growth at high external osmolarity is physiologically complex (Jennings, 1995). Generally, fungi are able to grow at elevated $\mathrm{NaCl}$ concentrations of 1.5 to $5 \mathrm{M}$ (Griffin, 1994) or even saturated salt solutions for extremophiles (Gostinčar et al., 2009). At such high external concentrations of osmotically active solutes, turgor has to decline (the cell is unlikely to have a cytoplasmic salt concentration higher than the saturated solution outside).

For non-extremophiles, the response to high extracellular osmoticum is complex. First, if the wall is elastic, the cell volume will shrink causing the internal osmolarity to increase. This can offset - to varying degrees - the higher external osmolarity. Second, if the cell takes up the external solute, this too will offset a decline in turgor. Finally, changes in the yield threshold of the wall may allow continued growth at lower turgor. Thus, the ability to grow at high external osmolarity may not depend solely upon active turgor regulation. Whether turgor itself is regulated has to be determined by its direct measurement.

There are a number of mutants that are osmosensitive, isolated on the basis of their inability to grow in $\mathrm{NaCl}(4 \% \mathrm{NaCl}$ is often used); the causes of their osmosensitivity vary (Radford, 2014). The bestknown Neurospora crassa mutants are the os (osmotic sensitive) mutants. Many of the os genes encode for components of a signal transduction cascade that induce multiple responses to high external osmotic shock and do play a role in turgor regulation (described later). There are other osmotic sensitive mutants, such as eas (easily wettable) and sor-4 (insensitive to growth restriction caused by sorbose). The wildtype eas gene encodes for hydrophobin, which creates a non-wettable, hydrophobic layer on conidia. The wildtype sor-4 encodes for a sugar sensor. So, osmosensitivity has many different underlying causes. I will focus on turgor and its regulation.

Direct evidence for relatively rapid turgor recovery of wildtype after hyperosmotic treatment is shown in figure 3 . Turgor levels under normal growing conditions do vary amongst osmotic sensitive mutants. Normal turgor values for mutants examined so far in Neurospora crassa are compiled in Figure 4A. Two of the mutants $(o s-1$ and $o s-2)$ are the osmosensor and final kinase in a MAP kinase cascade. When activated by high external osmoticum, they activate changes in ion transport across the plasma membrane and the synthesis of the osmolyte glycerol. Ion uptake and glycerol synthesis both contribute to recovery of turgor to initial levels (figure 4B). The dual responses of the signaling cascade operate differently. Increased 
glycerol synthesis requires changes in gene expression (Klipp et al., 2005) and is relatively slow (about 60 minutes) (Lew and Levina, 2007), while activation of ion uptake is direct (activating both the plasma membrane $\mathrm{H}^{+}$-ATPase and $\mathrm{K}^{+}$uptake) and faster (about 10 minutes) (Lew et al., 2006). Turgor recovery can rely solely on ion uptake, since the cut mutant - incapable of synthesizing glycerolregulates its turgor (Lew and Levina, 2007). Some of the other mutants that exhibit lower turgor under normal conditions (mid-1, $p t k-2$, and $p l c-1)$ probably play a regulatory role in downstream responses (figure $4 \mathrm{C}$ ).

Figure 4: Genes functioning in turgor regulation. A. The normal turgor values of a number of mutants can be similar to or lower than wildtype turgor. The data are shown as the percent of wildtype turgor measurements that were performed as controls for the experimental runs measuring the turgor of the mutants. Mutants that exhibit lower turgor are os -1 , os-2, mid-1, ptk-2, and plc-1. The os-1 and $o s-2$ genes are part of a MAP kinase cascade that functions in osmo-tolerance. The mid-1 gene encodes for a stretchactivated channel. The $p t k-2$ gene encodes for a protein that regulates ion transport activity (the plasma membrane $\mathrm{H}^{+}$-ATPase). The plc-1 gene encodes for a phospholipase C. B. For the mutants, various aspects of turgor regulation $\left(\mathrm{H}^{+}\right.$ATPase activation, $\mathrm{K}^{+}$and $\mathrm{Cl}^{-}$uptake, glycerol synthesis and turgor recovery) have been explored, although much remains to be done. $\mathrm{C}$. A diagrammatic description of the potential roles of the various genes examined so far.

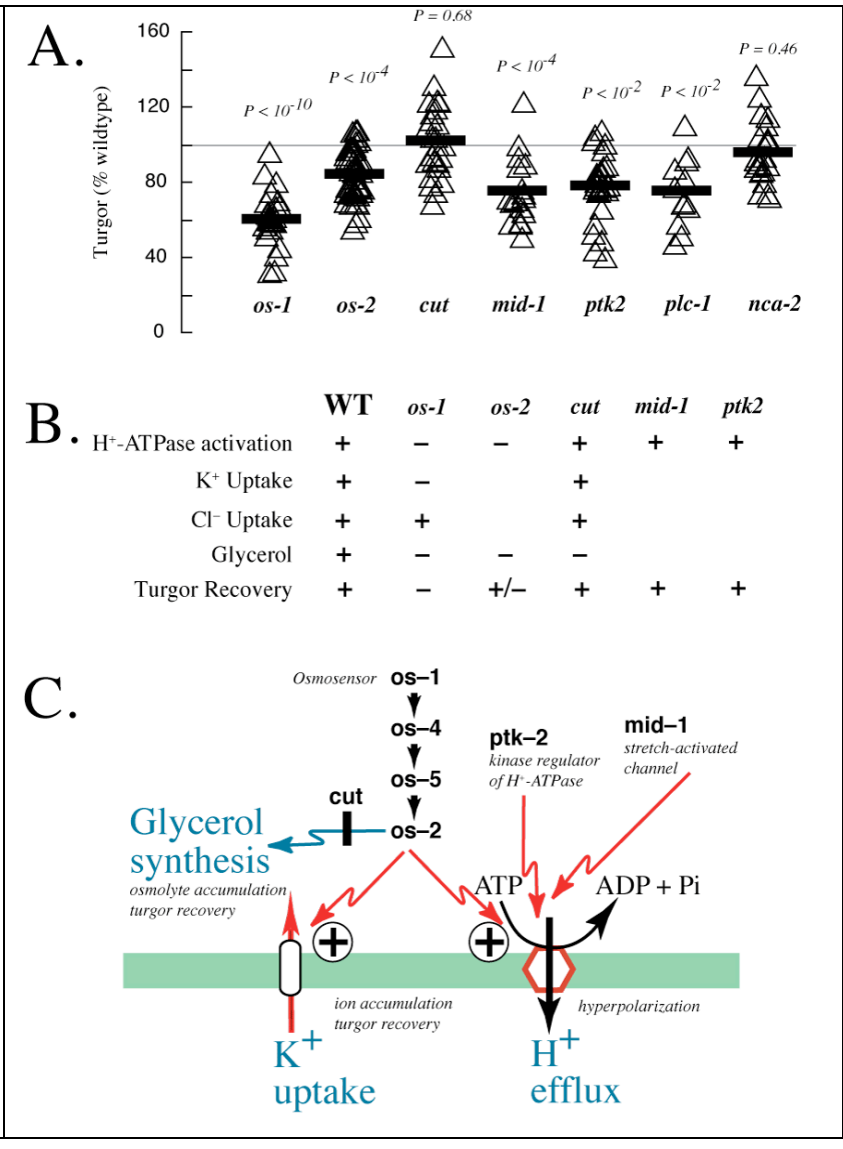

V. Cytoplasmic movement (mass flow)

The accumulation of ions and osmolytes maintains sustained hyphal elongation. But in addition, cytoplasm is recruited to the growing edge of the colony by mass flow (Lew, 2005). The driving force for mass flow is pressure differences along the hyphal tubes.

\section{A. Low Reynolds number hydrodynamics}

Mass flow in hyphae occurs at low Reynolds number (Reynolds, 1883). So, the flow is laminar, there is no turbulence. The Reynolds number is a dimensionless value, calculated from the equation: $\operatorname{Re}=$ ( @ $2 \mathrm{r}) / \eta$ where $\varrho$ is the density (about $1 \mathrm{gm} \mathrm{cm}^{-3}$ ), $v$ is the velocity of flow (about $5 \times 10^{-4} \mathrm{~cm} \mathrm{~s}^{-1}$ ), $2 \mathrm{r}$ is the diameter of the hyphal tube, and 
$\eta$ is the viscosity (similar to water, about $0.01 \mathrm{~g} \mathrm{~s}^{-1} \mathrm{~cm}^{-1}$ ). The value of $\mathrm{Re}$ is the ratio of inertial to viscous forces. At high Re, inertial forces dominate and flow is turbulent, at low values, viscous forces dominate, so that flow is laminar in nature. For cytoplasm movements in fungi, estimates of the Reynolds number are on the order of $10^{-}$. The Reynolds number at which turbulent flow will occur in a hydraulic pipe is on the order of 1 to $10^{3}$ (Brody et al., 1996).

At low Reynolds number the flow velocity can be estimated by the Hagen-Poisseulle equation: $v=\left(\left(\Delta P_{h, p h a l} / l\right) \mathrm{r}^{2}\right) /(8 \eta)$. The pressure gradient $\left(\Delta P_{\text {hyphal }} / l\right)$ required to cause velocities of $5 \times 10^{-4} \mathrm{~cm} \mathrm{~s}^{-1}$ is about $0.05 \mathrm{kPa} \mathrm{cm} \mathrm{cm}^{-1}$ (Lew, 2005). This is a very small pressure difference compared to the normal turgor of the hypha (400-500 $\mathrm{kPa})$.

The nature of mass flow through the hyphal tubes is complicated by the presence of organelles moving in the cytoplasmic stream. Experimental evidence of the non-ideal nature of flow is based on measurements of the velocity profile within the hypha. HagenPoisseulle predicts a parabolic shape, with maximal velocities at the center of the cylinder, tapering to zero at the hyphal walls. The actual profile is flat (Abadeh and Lew, 2013), a shape that is consistent with 'partial plug flow' (Cox and Mason, 1971).

Basically, the organelles moving within the tube (nuclei, mitochondria and vacuole velocity profiles have been mapped, Abadeh and Lew, 2013) modify the pattern of fluid shearing that would normally result in parabolic velocity profiles. Even so, estimates of the pressure gradients using Hagen-Poisseulle will not be that different from the pressure dependence of 'partial plug flow' (Cox and Mason, 1971).

\section{B. Effect of hyphal pores}

Do septal pores impede mass flow? The simple answer is: Not by much. The reason is that the pore may be smaller than the hyphal diameter, but the length of the pore is very short so the pore wall impedes flow over a very small distance, while the walls of the hyphal cylinder create a frictional drag over distances that are considerably longer.

Vogel (2003) provides a clear and straightforward explanation of the effect of pores and their relevance to mass transport in organisms besides fungi. Happel and Brenner (1986) provide a more complete

discussion. At low Reynolds number, the physical descriptions of flow through the hyphal tube and through the pore are different. For the first, the volumetric rate of flow $\left(\mathrm{Q}\right.$, in units of $\left.\mathrm{m}^{3} \mathrm{~S}^{-1}\right)$ is:

$$
Q=\frac{\Delta P_{\text {hyphal }}}{l} \cdot \frac{\pi \cdot R^{4}}{8 \cdot \eta}
$$

where $\Delta P_{\text {hrpata }} / l$ is the pressure gradient $\left(\mathrm{Pa} \mathrm{m}^{-1}\right), \mathrm{R}$ is the hyphal radius (m) and $\eta$ is the viscosity ( $\mathrm{Pa} \mathrm{s}$ ). For movement through a pore, the volumetric rate of flow is (Happel and Brenner, 1986): 


$$
Q=\frac{\Delta P_{\text {pore }} \cdot r^{3}}{3 \cdot \eta}
$$

where $\Delta P_{\text {pore }}$ is the pressure drop across the pore and $\mathrm{r}$ is the pore radius. An example of a calculation using values that are known for hyphae is presented in Figure 5. To assess the pressure drop in the hypha, I assumed a hyphal length of about $200 \mu \mathrm{m}$ between septa. I used a volumetric rate of flow of $7.85 \times 10^{-16} \mathrm{~m}^{3} \mathrm{~S}^{-1}$ that was calculated from a typical velocity of particle flow of $5 \mu \mathrm{m} \mathrm{s}^{-1}$. The pressure drop for mass flow in the $200 \mu \mathrm{m}$ length of hypha is about $0.40 \mathrm{~Pa}$. With a septal pore radius half of the hyphal diameter, the pressure drop for mass flow through the pore is about $0.2 \mathrm{~Pa}$. Thus, although the septal pore does impede flow, the effect is smaller than might be expected. Johansen (1930) explored a model system that is pertinent to flow through hyphal tubes and septal pores; his results matched the expected result (Happel and Brenner, 1986). In his experimental observations of flow lines through the pipe orifice, he found that the flow was completely laminar, and symmetrical on either side of the pore at very low Reynolds number (similar to hyphal flow).

Septal pores have relatively small effects of on cytoplasmic flow under normal conditions. When there is damage to the mycelial network that causes cytoplasmic loss from the pressurized hyphae, they must seal rapidly to protect the integrity of the cytoplasm. Thus, their formation (Lai et al., 2012) and mechanisms of pore closure are important to the survival of the hyphal organism. Regulation of septal pores also occurs under a variety of non-damaging environmental conditions (van Peer et al., 2009), and even in mitosis (Shen et al., 2014).

Figure 5: Micro-fluidics of a hypha. To compare flow through the hyphal cylinder and the narrower aperture of the septal pore, the pressure drops through a 200 micron cylindrical length and through an aperture that was $50 \%$ of the hyphal width were calculated for a volume flow of $7.85 \times 10^{-16} \mathrm{~m}^{3} \mathrm{~s}^{-1}$ ( $0.785 \mathrm{pl} \mathrm{s}^{-1}$, the flow that would occur for a cytoplasm velocity of $5 \mu \mathrm{m} \mathrm{s}^{-1}$ in a $20 \mu \mathrm{m}$ diameter hypha). The pressure drops for flow through the cylinder are similar in magnitude to the pressure drop for flow through the septal pore $(0.4 \mathrm{~Pa}$ compared to $0.2 \mathrm{~Pa})$. Thus, the pore has some effect - but not a large one- on flow through the hyphal network. Experimentally measured velocity profiles (Abadeh and Lew, 2013) are also shown in the diagram.

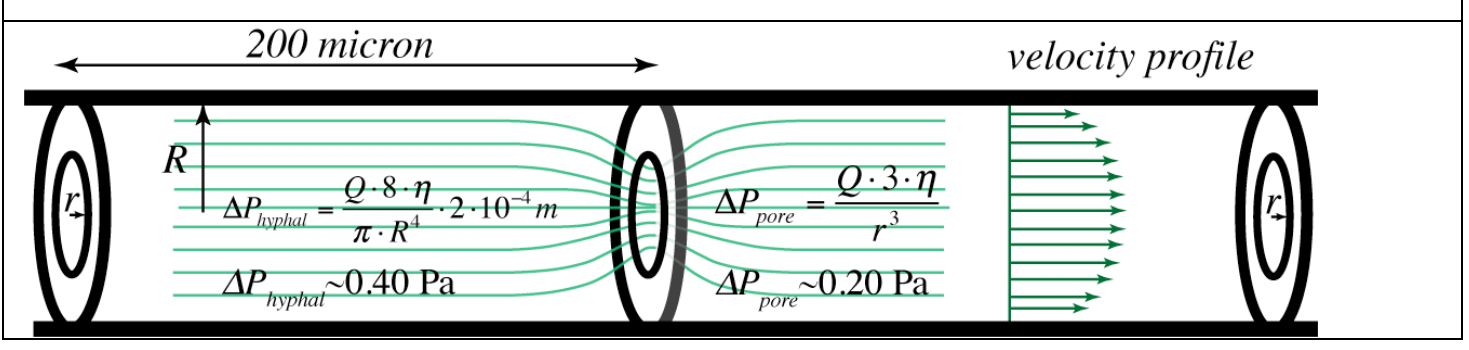

\section{Penetration (invasive growth)}

Another biomechanical aspect of hyphal growth is the ability of the hyphae to penetrate tissues or substrates. How much pressure does a hypha apply to penetrate a substrate? Bastmeyer et al., 2002), Money (2007) and Yafetto et al. (2009) explored aspects of this question for fungi. Indirect techniques and high sensitivity strain gauges can be 
used to measure the very small forces a small hypha will exert when growing into a substrate. Lab on a chip technologies are being pioneered for other tip-growing organisms as well, such as pollen tubes which must penetrate the stigma to effect successful pollination (Burri et al., 2018).

Adapting growth to penetrate substrates is related to two sensorresponse systems: chemotropism (Turrà et al., 2016) and thigmotropism (Almeida and Brand, 2017). The biochemical mechanisms underlying chemo- and mechano-sensing are very diverse, and generally result in activation of MAP kinase and cAMP signaling cascades (Turrà et al., 2016; Braunsdorf et al., 2016). The final result is to initiate penetration into substrate.

Substrate penetration by hyphae - whether into host tissue or ramifying through soil or other substrate- will depend upon physical force. These forces are small on an absolute scale. In Armillaria rhizomorphs, Yafetto et al. (2009) reported values of about 1-6 milliNewton, corresponding to a turgor of 40-300 kiloPascal. Can these pressures be use to mechanically penetrate a tissue or substrate? There is no direct answer. For example, as a hypha penetrates a tissue, the tip will naturally take the path of least resistance. In doing so, it can easily decrease the hyphal tip size to effect easier penetration. Finally, it can modify the structural integrity of the substrate through extracellular hydrolases to soften the substrate. None of these adaptive processes lend themselves to a simple biomechanical analysis. In this regard, recent advances using Lab on a Chip technologies should be useful. For example, Tayagui et al (2017) grew hyphae of Achlya bisexualis (an oomycete) through a micro-pillar array and measured pillar deflections to quantify the force applied by the hypha. Burri et al. (2018) coupled micro-channels with a microelectromechanical force-sensor to measure the forces at the tips of pollen tubes as they collided with and responded to the force-sensing barrier. In the future, these technical advances should provide methods to enlighten our understanding of fungal penetration of substrates. 


\section{Literature Cited}

Abadeh A, Lew RR (2013) Mass flow and velocity profiles in Neurospora hyphae: partial plug flow dominates intra-hyphal transport. Microbiology (SGM). 159:2386-2394.

Adams DJ (2004) Fungal cell wall chitinases and glucanases. Microbiology 150:2029-2035.

Almeida MC, Brand AC (2017) Thigmo responses: the fungal sense of touch. Microbiol Spectrum 5(2):FUNK-0040-2016. doi:10.1128/microbiolspec.FUNK-0040-2016.

Bartnicki-Garcia S, Bracker CE, Gierz G, López-Franco R, Lu H (2000) Mapping the growth of fungal hyphae: orthogonal cell wall expansion during tip growth and the role of turgor. Biophysical Journal 79:2382-2390.

Bastmeyer M, Deising HB, Bechinger C (2002) Force exertion in fungal infection. Annu. Rev. .Biophys. Biomolec. Struct. 31: $321-341$.

Braunsdorf C, Mailänder-Sánchez D, Schaller M (2016) Fungal sensing of host environment. Cellular Microbiology 18:1188-1200 doi:10.1111/cmi.12610

Brody JP, Yager P, Goldstein RE, Austin RH (1996) Biotechnology at low Reynolds numbers. Biophysical J. 71:34303441

Burri JT, Vogler H, Läubli NF, Hu C, Grossniklaus U, Nelson BJ (2018) Feeling the force: how pollen tubes deal with obstacles.

bioRxiv doi: https://doi.org/10.1101/266106

Cox RG, Mason SG (1971) Suspended particles in fluid flow through tubes. Annu. Rev. Fluid Mech. 3: 291-316. doi:10.1146/annurev.f1.03.010171.001451

Emerson S (1963) Slime, a plasmodial variant of Neurospora crassa. Genetica 34:162-182.

Free SJ (2013) Fungal cell wall organization and biosynthesis. Advances in Genetics 81:33-82.

Gostinčar C, Martin Grube M, De Hoog S, Zalar P, Gunde-Cimerman N (2009) Extremotolerance in fungi: evolution on the edge. FEMS Microbiology Ecology 71: 2-11.

Griffin DH (1994) Fungal Physiology. Wiley-Liss. New York. pp. 144.

Happel J, Brenner H (1986) Low Reynolds Number Hydrodynamics. Martinus Nijhoff. pp 153-154.

Harold RL, Money NP, Harold FM (1996) Growth and morphogenesis in Saprolegnia ferax: Is turgor required? Protoplasma 191, 105-114.

Heath IB, Steinberg G (1999) Mechanisms of hyphal tip growth: tube dwelling amebae revisited. Fung. Genet. Biol. 28:7993.

Hüsken D, Steudle E, Zimmerman U (1978) Pressure probe technique for measuring water relations of cells in higher plants. Plant Physiology 61:158-163.

Jennings DH (1995) The Physiology of Fungal Nutrition. Cambridge University Press. Cambridge. pp. 398-446.

Johansen FC (1930) Flow through pipe orifices at low Reynolds number. Proc. R. Soc. Lond. A 126:231-245. doi: 10.1098/rspa.1930.0004

Kaminskyj SGW, Garrill A, Heath IB (1992) The relation between turgor and tip growth in Saprolegniaferax: Turgor is necessary, but not sufficient to explain apical extension rates. Experimental Mycology 16:64-75.

Klipp E, Nordlander B, Kruger R, Gennemark P, Hoffmann S (2005) Integrative model of the response of yeast to osmotic shock. Nature Biotechnology 23:975-982.

Lai J, Koh CH, Tjota M. Pieuchot L, Raman V, Chandrababu KB, Yang D, Wong L, Jedd G (2012) Intrinsically disordered proteins aggregate at fungal cell-to-cell channels and regulate intercellular connectivity. Proc. Natl. Acad. Sci USA 109:15781-15786.

Lew RR (1996) Pressure regulation of the electrical properties of growing Arabidopsis thaliana L. root hairs. Plant Physiology. 112:1089-1100.

Lew RR (2005) Mass flow and pressure-driven hyphal extension in Neurospora crassa. Microbiology 151:2685-2692.

Lew RR (2011) How does a hypha grow? The biophysics of pressurized growth in fungi. Nature Reviews Microbiology. 9:509-518.

Lew RR, Levina NN, Walker SK, Garrill A (2004) Turgor regulation in hyphal organisms. Fungal Genetics and Biology. 41:1007-1015.

Lew RR, Levina NN, Shabala L, Anderca MI, Shabala SN (2006) Role of a mitogen-activated protein kinase cascade in ion flux-mediated turgor regulation in fungi. Eukaryotic Cell. 5:480-487. 
Lew RR, Nasserifar S (2009) Transient responses during hyperosmotic shock in the filamentous fungus Neurospora crassa. Microbiology (SGM). 155:903-911.

Lintilhac PM, Wei C, Tanguay JJ, Outwater JO (2000) Ball tonometry: A rapid, nondestructive method for measuring cell turgor pressure in thin-walled plant cells. Journal of Plant Growth Regulation 19:90-97. DOI: 10.1007/s003440000009

Lockhart JA (1965) An analysis of irreversible plant cell elongation. Journal of Theoretical Biology 8:264-275.

Money NP (2007) Biomechanics of invasive hyphal growth. In Howard RJ and NAR Gow (eds.) Biology of the Fungal Cell, 2nd Edition. The Mycota VIII. Springer-Verlag Berlin Heidelberg. pp. 237-249.

Niklas KJ, Spatz H-C (2012) Plant Physics. University of Chicago Press.

Nobel PS (1991) Physicochemical and Environmental Plant Physiology. Academic Press. San Diego.

Perkins DD, Radford A, Newmeyer D, Björkman M (1982) Chromosomal loci of Neurospora crassa. Microbiol. Rev. 46:426-570.

Proseus TE, Boyer JS (2006) Calcium pectate chemistry controls growth rate of Chara corallina. J. Exp. Bot. 57:3989-4002.

Proseus TE, Boyer JS (2007) Tension required for pectate chemistry to control growth in Chara corallina. J. Exp. Bot. 58:4283-4292.

Radford A (2014) (curator) The Neurospora crassa e-Compendium.

http://www.bioinf.leeds.ac.uk/ gen6ar/newgenelist/genes/index.html (accessed 3 September 2014)

Reynolds O (1883) An experimental investigation of the circumstances which determine whether the motion of water shall be direct or sinuous, and of law of resistance in parallel channels. Phil. Trans. Roy. Soc. London 174: 935-982.

Shen K-F, Osmani AH, Govindaraghavan M, Osmani SA (2014) Mitotic regulation of fungal cell-to-cell connectivity through septal pores involves the NIMA kinase. Mol. Biol. Cell 25:763-775.

Tayagui A, Sun Y, Collings DA, Garrill A, Nock V (2017) An elastomeric micropillar platform for the study of protrusive forces in hyphal invasion. Lab Chip 17:3643. DOI: 10.1039/c7lc00725f

Turrà D, Nordzieke D, Vitale S, El Ghalid M, Di Pietro A (2016) Hyphal chemotropism in fungal pathogenicity. Semin. Cell Dev. Biol. 57:69-75. doi:10.1016/j.semcdb.2016.04.020.

van Peer AF, Müller WH, Boekhout T, Lugones LG, Woösten HAB (2009) Cytoplasmic continuity revisited: Closure of septa of the filamentous fungus Schizophyllum commune in response to environmental conditions. PLoS ONE 4:e5977 doi:10.1371/journal.pone.000597.

Vogel S (2003) Comparative Biomechanics. Life's physical world. Princeton University Press. pp 187-203.

Walker SK, Chitcholtan K, Yu Y-P, Christenhusz GM, Garrill A (2006) Invasive hyphal growth: An F-actin depleted zone is associated with invasive hyphae of the oomycetes Achlya bisexualis and Phytophthora cinnamomi. Fung. Genet. Biol. 43:357-365.

Yafetto L, Davis, DJ, Money NP (2009) Biomechanics of invasive growth by Armillaria rhizomorphs.

Fung. Genet. Biol. 46:688-694.

Zimmerman U (1978) Physics of turgor- and osmoreguation. Annual Review of Plant Physiology 29:121-148

Zimmerman U, Räde H, Steudle E (1969) Kontinuierliche druckmessung in pflenzenzellen. Naturwissenschaften 56(12):634.

\section{Terms for Indexing}

Cytoplasmic movement

Elasticity

Hydrodynamics

Mass flow hydrodynamics, septal pore

Osmotolerance

Plasticity

Reynolds number, low

Turgor

Strain turgor regulation

Stress, tensional

Viscoelasticity 